Research Article

\title{
Sensation Seeking, Peer Influence, and Risk-Taking Behavior in Adolescents
}

\author{
R. Siraj (iD, B. Najam (D), and S. Ghazal $(\mathbb{D}$ \\ Institute of Applied Psychology, University of Punjab, Lahore, Pakistan \\ Correspondence should be addressed to R. Siraj; rabiasiraj9@gmail.com
}

Received 7 February 2020; Revised 29 January 2021; Accepted 1 March 2021; Published 10 March 2021

Academic Editor: Haoran Xie

Copyright $\odot 2021$ R. Siraj et al. This is an open access article distributed under the Creative Commons Attribution License, which permits unrestricted use, distribution, and reproduction in any medium, provided the original work is properly cited.

\begin{abstract}
This research was conducted to explore the relationship between sensation seeking, peer influence, and risk-taking behavior in adolescents and moderating role of peer influence for sensation seeking and risk-taking behavior. A sample comprised 200 adolescents with age range $10-18$ years $(M=17.57, \mathrm{SD}=0.98)$. Assessment measures included Resistance to Peer Influence Scale (Steinberg and Silverberg (1986)), Brief Sensation Seeking Scale (Prinstein et al. (2003)), and Stimulating and Instrumental Risk questionnaire (Ravert et al. (2009)) and a demographic information sheet. Findings of Pearson product moment analysis revealed that there was a significant positive relationship between sensation seeking and risk-taking behavior in adolescents and there was a significant positive relationship between peer influences and risk-taking behavior in adolescents. Gender differences were observed; male participants scored higher on sensation seeking and risk-taking behavior than female participants, but on peer influence, females scored higher than males. Moderation analysis through hierarchical regression was conducted and findings of this analysis revealed that sensation seeking positively predicted risk-taking behavior and peer influences also positively predicted risk-taking behavior in adolescents but no interaction effect was observed between sensation seeking and peer influence in predicting risk-taking behavior. Moreover, subscales of sensation seeking, i.e., adventure seeking and disinhibition, predicted risktaking behavior. Results are discussed in terms of their implications.
\end{abstract}

\section{Introduction}

Puberty is a period of main alteration in developing attitude towards life. During adolescence, there are many factors, including bodily, mental, emotional, and social alterations, taking place among adolescents and these factors may increase inclination in adolescents to take risks. These factors are fundamental or influential in nature at social and interpersonal level [1]. Social influence is an environmental factor that leads to adolescent risk-taking behavior. Peer groups influence adolescent's socialization and individuality by allowing adolescents to discover their interests and uncertainties while holding a sense of joining a group of friends. Adolescents like to go for unique, complicated, and extreme sensations and like experience for its own sake and engage in risk-taking behavior in the pursuit of such experiences [2].
Sensation seeking is a personality trait defined as the looking for diverse, new, complex, and extreme level of sensations and the motivation to take physical, social, authorized, and economic risks [3]. Sensation seeking activities particularly licit and illicit recreational drug consumption, risky driving, or sexual behaviors covaries in both adults and adolescents [4].

Zuckerman [3] described two forms of sensation seeking as unsocialized sensation seeking and socialized sensation seeking. Unsocialized sensation seeking is impulsive and it has three subcategories: disinhibit ion, experience seeking, and boredom susceptibility. Socialized sensation seeking is non-impulsive and it has one subcategory which was described as the thrill and adventure seeking. The concept of sensation seeking starts with Zuckerman's idea that every individual has a most promising level of motivation [3]. Stimulation is considered any action or situation that 
provokes a response. The response produced by stimulation is a state of increased physical activity known as arousal [3].

Theory of optimal level of stimulation described the individual has a range of strength of motivation and sensation. With this range, there was an optimal point where an incentive was found most enjoyable to the individual. The individual perceives the incentive as less pleasant or disinterested when anything is above or below this optimal level [3].

Theory of optimal level of arousal was grounded on the notion that human's level of stimulation is maintained by the reticular activating system in the body. Any level exceeding this optimal level of arousal produces a requirement to decline stimulation which leads to sensation avoidance. Any level below this optimal level of arousal produces a requirement to raise stimulation which leads to sensation seeking [5]. Sensation seeking levels may be influenced by a person's own experiences or even learned from observed outcomes of others experiences. For instance, individuals may learn to model certain sensation seeking behaviors if the outcome they experience is helpful and positive or avoids being more involved in the sensation seeking behavior if the consequences of the experiences are negative [3].

Sensation seeking is related to perception of risk-taking behavior such as health, social, economic, and legal which typically gratifies the high sensation in adolescent's desire for new and extreme experiences. The susceptibility to risk-taking in adolescence may be due to the grouping of relatively higher predispositions to seek excitement and relatively unformed capacities for self-control that are typical in this age of development [6].

However, dissenting views and recent research term sensation-seeking is a personality trait found to be correlated with positive and negative risk-taking behavior $[7,8]$, reckless behavior [9], consumption of alcohol, increases in the quantity of alcohol students consumed at any given drinking episode, and negative outcomes experienced from drinking [10], impulsivity, risky behaviors and gambling [11], invulnerability as predictors of health compromising behaviors such as substance use which impaired driving and sexual behavior [12], as well as nadequate sleep depression, injuries, violent behavior, and smoking [13].

Boys having sensation seeking personality trait are likely to involve in risk taking behaviors as compared to girls [14]. Moreover, disinhibition and stress were predictors of Internet abuse for sexual purposes in boys and hopelessness and boredom susceptibility were predictors of Internet abuse for nonsexual purposes in boys $[15,16]$.

The susceptibility to risk-taking in adolescence may be due to the grouping of relatively higher inclinations to seek excitement, pressure from peer group, and relatively immature capacities for self-control that are typical of this period of development. Peer influences and sensation seeking appear to mutually reinforce each other in the development of risk-taking behavior [17].

Ryan [18] described peer influence as when the people of your own age pressurize and reinforce you to do something and support you to keep away doing something else; it does not matter if you personally need to do it or not. Peer influence comprises altering one's behavior to meet the apparent hope and desire of others. A negative peer influence is described as where peers are seen to wish a teen to do something risky, which often leads to death. Adolescents have been recognized to have selected an incorrect route of life by taking to substance abuse, excessive consumption of alcohol smoking, drug use, stealing and shoplifting, etc. Such activities often lead to a criminal record and make hurdles in bright educational career [19]. Peer influencers are not constantly negative. Positive peer influences motivate adolescents to take part in religious activities, and playing games, even when they are not leaders. The peer group is a basis of love, sympathy, understanding and a place for experimentation [20].

Peer influence is an essential factor in adolescent risktaking behavior; adolescents are more likely to be involved in such kinds of dangerous behavior when they are with their peers rather than when they are alone. Adolescents are more engaged in risky activities such as smoking, drug use, and reckless driving etc. for the sake of social acceptance and social conformity [21]. Several possible explanations describe the association between deviant peer association or the presence of peers and risk-taking behavior of adolescents.

First, a literal explanation of peer influence proposes that peer groups socialize adolescents in specific risk-taking behaviors. Research from social learning approaches like Problem Behavior Theory describes possible ways by which modeling and reinforcement of deviant behavior may initiate adolescents into a culture of risk-taking, although the social learning perspective is consistent with extensive correlational evidence linking adolescent risk-taking to deviant peer affiliation [22].

A second approach is theory of planned behavior that describes the process of social influences and their effects on intentions about behaviors which in turn lead to actual involvement in particular behaviors. Individual involvement in particular behaviors depends on his/her positive and negative assessments about it. These assessments many times are based on their knowledge as well as the social influences or pressures put on them [23].

A third approach is social action theory which states that behavior of people based on peer influences or a general society perception and theses behavior results in negative and positive outcomes. Individual vulnerability of engaging in behaviors can be influenced by his colleague's expectations. Individuals follow their group values to avoid rejection from his peer group and engage in behavior for the sake of group conformity [24].

However, different researches in the previous literature showed that adolescence is a period of life in which peer relationships become increasingly important. Adolescents have a greater likelihood to be influenced and involved in risk-taking behavior due to their socialization and for the sake of peer conformity. Young adolescents were more strongly influenced by the teenager social-influence group than their parents and the adult social-influence group $[25,26]$. Adolescents have a great likelihood to be influenced and involved in different types of socially proscribed 
activities such as tobacco use, alcohol use, and engagement in risky sexual behaviors for the sake of peer conformity [27], deviant behavior in adolescents, and this relationship is associated with adolescent substance use, abuse $[28,29,2]$ vandalism, and substance use to homicide with their peer groups [30]. Boys were more influenced from their peer group and engaged in smoking than girls due to peer pressure [32].

In the light of above-mentioned literature, the current study was aimed at exploring the relationship between sensation seeking, peer influence, and risk-taking behavior in adolescents and moderating role of peer influence for sensation seeking and risk-taking behavior. Another aim of current study was to find out gender differences between sensation seeking peer influences and risk-taking behavior in adolescents. It was hypothesized that sensation seeking was likely to have a positive relationship with risk-taking behavior in adolescents. Another assumption was that peer influences were positively correlated with risk-taking behavior in adolescents. Moreover, it was also hypothesized that peer influences would moderate the relationship between sensation seeking and risk-taking behavior in adolescents.

Figure 1 shows the hypothesized model of study.

\section{Methods}

2.1. Sample. The sample comprised 100 male and 100 female students of ages between 10 and 18 years $(M=17.57$, $\mathrm{SD}=0.98)$ from different colleges. Data were collected from government colleges of Lahore. Public sector colleges were selected through convenient sampling. Four girls and four boys colleges were selected. Students were selected through convenient sampling. Both first- and second-year students were included. Students with separated parents were excluded. Students living in hostels were excluded. A description of the sample is given in Table 1.

Table 1 shows frequencies and percentage of demographic variables.

2.2. Assessment Measures. Demographic information sheet: demographic information was collected through demographic sheet which included age, gender, education, father education, mother education, birth order, family system, Internet facility, availability of Internet, and spending time with friends.

2.2.1. Sensation Seeking Scale. The Brief Sensation Seeking Scale (BSSS) was used to assess the level of sensation seeking in adolescents and young adults which was developed by Stephenson [32]. This measure was used because it appropriately measures the construct under study. The questionnaire included eight items under four subscales: Experience Seeking, Boredom Susceptibility, Thrill and Adventure Seeking, and Disinhibition. Each subscale includes two items. For example, I prefer friends who are excitingly unpredictable. Responses to each item were indicated on a Likert scale (i.e., 1=strongly disagree,

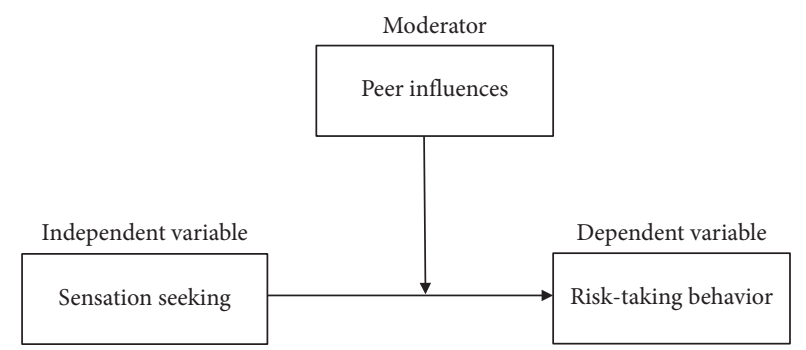

FIGURE 1: Hypothesized model of research showing sensation seeking as IV, peer influences as moderator, and risk-taking behavior as DV [17].

TABle 1: Descriptive, frequencies, and percentage of demographic variables $(N=200)$.

\begin{tabular}{|c|c|c|}
\hline Variables & $f$ & $\%$ \\
\hline \multicolumn{3}{|l|}{ Age } \\
\hline \multicolumn{3}{|l|}{ Gender } \\
\hline Boys & 100 & 50 \\
\hline Girls & 100 & 50 \\
\hline \multicolumn{3}{|l|}{ Education } \\
\hline First-year & 130 & 65.0 \\
\hline Second-year & 70 & 35.05 \\
\hline \multicolumn{3}{|l|}{ Father education } \\
\hline Uneducated & 35 & 17.5 \\
\hline Primary to metric & 92 & 46 \\
\hline Intermediate & 33 & 16.5 \\
\hline Bachelors and above & 40 & 20 \\
\hline \multicolumn{3}{|l|}{ Mother education } \\
\hline Uneducated & 55 & 27.5 \\
\hline Primary to metric & 100 & 50 \\
\hline Intermediate & 24 & 12.0 \\
\hline Bachelors and above & 20 & 10 \\
\hline \multicolumn{3}{|l|}{ Family system } \\
\hline Nuclear & 126 & 63.0 \\
\hline Joint & 74 & 37.0 \\
\hline \multicolumn{3}{|l|}{ Birth order } \\
\hline First & 100 & 50 \\
\hline Middle & 87 & 43.5 \\
\hline Last & 12 & 6.0 \\
\hline \multicolumn{3}{|l|}{ Internet facility } \\
\hline No & 40 & 20.0 \\
\hline Yes & 160 & 80.0 \\
\hline \multicolumn{3}{|l|}{ Spend time with friends } \\
\hline No & 61 & 30.5 \\
\hline Yes & 139 & 69.5 \\
\hline
\end{tabular}

$2=$ disagree, $3=$ neither disagree nor agree, $4=$ agree, and $5=$ strongly agree). The reliability of the BSSS was 0.76. In the present research, scale was translated into Urdu by following the Mappi Guidelines.

2.2.2. Resistance to Peer Influence Scale. The Resistance to Peer Influence Scale assesses levels of resistance in neutral situations. The paper [34] developed resistance to peer influences scale. The scale included 10 pairs of statements that describe types of people. For each pair, one statement reflects people who are resistant to peer influence and the other reflect those who are susceptible. For example, some people 
go along with their friends just to keep their friends happy. But, other people refuse to go along with their friends want to do, even though they know it will make their friends unhappy. Responses to each pair of items were indicated on a Likert scale $(1=$ sort of true or $2=$ really true). The reliability coefficient was 0.73 . Translated Urdu version was used in the study. Scale was translated through proper use of Mappi guidelines.

\subsubsection{Stimulating and Instrumental Risk-Taking Questionnaire.} Risk-taking behavior was measured through stimulating and instrumental risk-taking questionnaire [12]. The questionnaire consisted of seventeen items under two subscales: stimulating and instrumental risk-taking. Stimulating risktaking includes ten items. For example, I enjoy risk-taking. Instrumental risk-taking included seven items, for example, to achieve something in life one has to take risks. Responses to each item were indicated on five-point Likert scale (i.e., $1=$ not for sure, $2=$ rather not, $3=\mathrm{I}$ do not know, $4=$ rather yes, $5=$ yes for sure). Reliability of stimulating and instrumental risk-taking questionnaire was 0.70 . Translated Urdu version was used in the study. Scale was translated through proper use of Mappi guidelines.

2.3. Procedure. The tools were used after taking the permission from authors of questionnaires. Permission letter provided by the head of Institute of Applied Psychology was signed from the supervisor and then permission from heads of respective colleges was taken then. Data was collected on convenience base and questionnaires were administered to students individually or in class or in computer labs. Consent from the students was taken and they were assured that their confidentiality will not be disclosed. Three colleges did not allow collecting data from their students. Time taken for completion of the questionnaire was 15 to 20 minutes. Overall response rate was $85.1 \%$. Approximately twenty students withdrew from study and refused to give information and fifteen questionnaires were discarded as they were incomplete.

\section{Results}

Pearson Product Moment Correlation and moderation through multiple hierarchical regression analysis were used to analyze study variables, as shown in Table 2.

As shown in Table 2, results of Pearson product moment correlation analysis revealed that sensation seeking was not significantly correlated with age. Experience seeking and boredom susceptibility were positively correlated with age while no significant relationship was found between age and thrill and adventure seeking and disinhibition. Moreover, peer influences were not significantly correlated with age. There was a significant positive relationship in age and total risk-taking behavior. While no significant positive relationship was found between age and stimulating risk-taking behavior, there was a significant positive relationship in age and instrumental risk-taking behavior. Furthermore, gender had a significant negative relationship with sensation seeking and with its four subscales, i.e., experience seeking, thrill and adventure seeking, disinhibition and boredom susceptibility, and risktaking behavior too, which depict that boys score higher on sensation seeking and all subscales of sensation seeking and risk-taking behavior as compared to girls, while gender had a significant positive relationship with peer influences which means that girls scored higher on peer influence as compared to boys.

This table further illustrates that there was significant positive relationship between sensations seeking with its four subscales experience seeking, thrill and adventure seeking, disinhibit ion, and boredom susceptibility. There was a significant positive relationship between sensation seeking and risk-taking behavior and its subscales, i.e., stimulating risk-taking behavior and instrumental risktaking behavior. Furthermore, the results revealed a significant positive relationship between peer influences and risk-taking behavior and stimulating risk-taking behavior while no relationship with instrumental risk-taking behavior.

In addition, in order to analyze the moderating role of peer influence for sensation seeking and risk-taking behavior, moderation analysis through hierarchical regression was done to estimate the extent to which sensation seeking and peer influence predict risk-taking behavior independently and how the interaction between sensation seeking and peer influence predicts risk-taking behavior.

Among the variables, gender was entered in first block and sensation seeking was entered in the second block and peer influence was entered in third block and interaction of peer influences and sensation seeking were entered in the fourth block to check the interaction effect. Interaction terms were obtained by multiplying centered peer influences with centered sensation seeking scores.

Table 3 presents the results of moderation analysis for student's risk-taking behavior as criterion variable. Gender was entered in block 1 that explained 10\% variance in risktaking behavior and it was significant, $F(1,199)=23.06$, $p=<0.001$. In the second block after adding sensation seeking, it explained $41 \%$ variance in risk-taking behavior that was significant $F(2,199)=69.04, p=<0.001$. In the third block after adding peer influence, it explained $45 \%$ variance in risk-taking behavior that was significant $F$ $(3,199)=53.97, p=<0.001$ and product of peer influences and sensation seeking was entered in block 4; overall model explained $45 \%$ variance in risk-taking behavior which was significant too $F(2,199)=40.47, p=<0.001$. Findings showed that sensation seeking positively predicted risktaking behavior $(\beta=0.61, p=<0.001)$ and peer influences positively predicted risk-taking behavior $(\beta=0.21$, $p=<0.001)$ but the interaction of sensation seeking and peer influence $(\beta=-0.04, p=0.64)$ did not significantly predict the risk-taking behavior of adolescents.

Moreover, moderation analysis through multiple hierarchical regressions was applied to check prediction and interaction of subscales of sensation seeking with peer influence for risk-taking behavior [17]. 
TABLE 2: Pearson product moment correlation between sensation seeking, peer influences, and risk-taking behavior in adolescents $(N=200)$.

\begin{tabular}{|c|c|c|c|c|c|c|c|c|c|c|}
\hline Variables & 2 & 3 & 4 & 5 & 6 & 7 & 8 & 9 & 10 & 11 \\
\hline 1. Age & -0.23 & 0.06 & $0.13^{*}$ & -0.03 & -0.06 & $0.17^{* *}$ & 0.01 & $0.13^{*}$ & 0.06 & $0.16^{*}$ \\
\hline 2. Gender & & $-0.41^{* *}$ & $-0.20^{* *}$ & $-0.23^{* *}$ & $-0.39^{* *}$ & $-0.36^{* * *}$ & $0.18^{*}$ & $-0.32^{* * *}$ & $-0.26^{* * *}$ & $-0.26^{* * *}$ \\
\hline 3. Sensation seeking & & - & $0.65^{* * *}$ & $0.77^{* * *}$ & $0.81^{* * *}$ & $0.69^{* * *}$ & -0.06 & $0.63^{* * *}$ & $0.54^{* * *}$ & $0.49^{* * *}$ \\
\hline 4. Experience seeking & & & - & $0.37^{* * *}$ & $0.35^{* * *}$ & $0.25^{* * *}$ & 0.04 & $0.35^{* * *}$ & $0.31^{* * *}$ & $0.27^{* * *}$ \\
\hline 5. Thrill and adventure seeking & & & & - & $0.56^{* * *}$ & $0.35^{* * *}$ & -0.00 & $0.61^{* * *}$ & $0.50^{* * *}$ & $0.49^{* * *}$ \\
\hline 6. Disinhibition & & & & & - & $0.43^{* * *}$ & -0.03 & $0.55^{* * *}$ & $0.50^{* * *}$ & $0.39^{* * *}$ \\
\hline 7. Boredom susceptibility & & & & & & - & $-0.19^{*}$ & $0.35^{* * *}$ & $0.27^{* * *}$ & $0.30^{* * *}$ \\
\hline 8. Peer influences & & & & & & & - & $0.14^{*}$ & $0.17^{* *}$ & 0.06 \\
\hline 9. Total risk-taking & & & & & & & & - & $0.83^{* * *}$ & $0.73^{* * *}$ \\
\hline 10. Stimulating risk-taking & & & & & & & & & - & $0.33^{* * *}$ \\
\hline 11. Instrumental risk-taking & & & & & & & & & & - \\
\hline
\end{tabular}

Note. ${ }^{*} p=<0.05 ;{ }^{* *} p=<0.01 ;{ }^{* * *} p=<0.001$

TABLE 3: Multiple hierarchical regression (moderation) analysis predicting risk-taking behavior from sensation seeking and peer influences $(N=200)$.

\begin{tabular}{|c|c|c|}
\hline \multirow{2}{*}{ Predictors } & \multicolumn{2}{|c|}{ Risk-taking behavior } \\
\hline & $\Delta R^{2}$ & $\mathrm{~B}$ \\
\hline \multicolumn{3}{|l|}{ Constant } \\
\hline Bock 1 & $0.10^{* * *}$ & \\
\hline Gender & & 0.12 \\
\hline Block 2 & $0.31^{* * *}$ & \\
\hline Sensation seeking & & $0.60^{* * *}$ \\
\hline Block 3 & $0.4^{* * *}$ & \\
\hline Peer influence & & $0.21^{* * *}$ \\
\hline Block 4 & 0.001 & \\
\hline Sensation seeking and peer influence & & -0.04 \\
\hline Total $R^{2}$ & $0.45^{* * *}$ & \\
\hline
\end{tabular}

Note. ${ }^{* * *} p=<0.001$.

Multiple hierarchical regression was applied for subscales of risk-taking behavior and overall risk-taking behavior (see Table 4). Gender was entered in block 1, which explained $10 \%$ variance in overall risk-taking behavior which was significant, $F(1,198)=23.06, p=<0.001$. In the second block, after adding subscales of sensation seeking, i.e., experience seeking, adventure seeking, disinhibition, and boredom susceptibility, it explained $45 \%$ variance in overall risk-taking behavior that was significant $F(5,194)=$ 32.80, $p=<0.001$. Then, peer influence was entered in the third block, which explained variance of $49 \%$ in overall risktaking behavior and it was significant $F(6,193)=31.69$, $p=<0.001$. Then, product of peer influence and sensation seeking subscales were entered in block 4; overall model explained the $50 \%$ variance in risk-taking behavior which was significant too, $F(10,189)=19.26, p=<0.001$. The findings showed that gender negatively predicted risk-taking behavior $(\beta=-0.12, p=<0.05)$, and peer influence positively predicted risk-taking behavior seeking $(\beta=0.19$, $p=<0.001)$, adventure seeking $(\beta=0.39, p=<0.001)$, and disinhibition $(\beta=0.23, p=<0.01)$ which predicted risktaking behavior but interaction of subscales of sensation seeking and peer influence was not significant.

\section{Discussion}

The age of adolescents was considered as complex due to the quick physical and psychological alteration as well as cumulative stresses from their peers. The present research was designed to explore the association in sensation seeking, peer influences, and risk-taking behavior as well as the moderating role of peer influences in sensation seeking and risktaking behavior in adolescents. Inferential statistics were used on the variables: sensation seeking, peer influences, and risk-taking behavior to find out the result of the research.

The first hypothesis of the study was that sensation seeking would have positive relationship with risk-taking behavior in adolescents. Findings proposed that sensation seeking was positively correlated with risk-taking behavior in adolescents. These findings are consistent with the earlier findings [7-9, 11, 12]. All these findings suggested that sensation seeking was positively correlated with risk-taking behavior in adolescents. Adolescence is one of the most exciting developing periods in a person's life. They want to explore different kinds of novel activities of adult life. However, different alteration in their social, biological, and psychological environment took place in adolescence 
TABLE 4: Multiple hierarchical regression (moderation) analysis predicting risk-taking behavior from subscales of sensation seeking and peer influences $(N=200)$.

\begin{tabular}{|c|c|c|}
\hline \multirow[t]{2}{*}{ Predictors } & \multicolumn{2}{|c|}{$\begin{array}{c}\text { Risk-taking } \\
\text { behavior }\end{array}$} \\
\hline & $\Delta R^{2}$ & $\mathrm{~B}$ \\
\hline Block 1 & $0.10^{* * *}$ & \\
\hline Gender & & $-0.12^{*}$ \\
\hline Block 2 & $0.35^{* * *}$ & \\
\hline Experience seeking & & 0.07 \\
\hline Adventure seeking & & $0.39^{* * *}$ \\
\hline Disinhibition & & $0.23^{* *}$ \\
\hline Boredom susceptibility & & 0.09 \\
\hline Block 3 & $0.04^{* * *}$ & \\
\hline Peer influence & & $0.19^{* * *}$ \\
\hline Block 4 & 0.01 & \\
\hline Experience seeking and peer influence & & -0.05 \\
\hline Adventure seeking and peer influence & & 0.15 \\
\hline Disinhibition and peer influence & & -0.15 \\
\hline Boredom susceptibility and peer influence & & -0.002 \\
\hline Total $R^{2}$ & $0.50^{* * *}$ & \\
\hline
\end{tabular}

development making them susceptible to encompassing in risky activities [9].

Another explanation might be that sensation seeking is a core feature of personality and characterized by different, new, difficult, extreme practices and readiness to be involved in physical, societal, authorized, and economic risks. Those who have the innate ability to engage in novel activities without considering the outcomes which is the major underlying phenomenon involved in sensation seeking and it supports the findings of the study that students who had the susceptibility to involve in new activities leads them towards risk taking behavior [9].

The second hypothesis of the current study was that peer influences would positively correlate with risk-taking behavior in adolescents. Findings of the current study revealed that peer influences were positively correlated with risktaking behavior in adolescents. These findings are consistent with the earlier findings in [25-29, 34, 35]. One reason of consistent findings might be that those adolescents who strongly perceived the behaviors and activities of the peers of their own age were most likely to participate in risky activities. They justified their own behaviors by using their perception of their peers' participation in risky behaviors [36].

Another reason of the results of the current study might be the media influence on adolescents. The showbiz industry often has been accused of encouraging adolescent's risky behaviors through depiction of unhealthy activities. Different television and social media videos depicted that the occurrence of injury-dangerous activities by characters far surpasses modeling of safety behaviors as well as it was also shown that risky behaviors did not have any consequences of injury and damage that also motivate adolescents to be involved in risky activities [32]. Furthermore, gender differences were also observed in Pearson product moment correlation analysis which depicted that boys scored higher in sensation seeking and risk-taking behavior as compared to girls and girls scored higher on peer influence as compared to boys. These findings are consistent with earlier findings $[14,15,31]$.

An enlightenment of the findings might be the difference in the opinion of parents as they allow boys to travel far from home, overnight parties, and play alone more than girls, and their participation in these kinds of social parties plays an important role in engaging risky behaviors [37]. Another reason could be the cultural features that explained that boys have different personality and biological characteristics than girls and it could be described as being a boy was a pointer to have more chances to get autonomy, independence, and high level of engaging in activities that predisposed them to behave more impulsively than girls [32]. Moreover, subscale of sensation seeking, i.e., adventure seeking and disinhibition, predicted risk-taking behavior. These findings are consistent with previous research results $[16,38]$. One reason for these findings might be adolescents' motivation in order to be involved in new activities for the sake of achieving adventure and these self-governing deeds are related to some risk such as drugs, reckless driving, and sexual activities. Moreover, another cause of results might be the reward system of brain that begins to develop in the early stage of adolescence as all areas of brain are not mature at this time and increased releases of dopamine stimulate the reward system of the brain that plays an important role in the engagement of adventure seeking that results in the participation in dangerous risky activities. Another cause of consistent finding might be lack of impulse control and less monitoring from their guardians that places youth at risk for negative consequences due to their engagement in risky kind of behaviors [33]. Adolescents predisposition towards dangerous behaviors had multi-determined outcome and it was caused by different parental, social personal reasons. In the present study, it was concluded after the results that adolescents who had tendency of sensation seeking and highly influenced by their peers were more likely to participate in risky kind of behavior and it was also confirmed that boys had a strong perception of engaging in dangerous behaviors than girls. Although this research will be helpful in understanding the perception of risk-taking behavior in adolescents, it would be helpful in guiding the developing adults about their engagement in risky behaviors due to the bad company of their friends as they are involved in such kind of activities because their peers are doing the same and it would be helpful in dropping their participation in these behaviors.

Correlational research design was used and it does not explain causation. It only explains relationship among variables. Further study in this area needs to be conducted with experimental research design. Data for present study was only collected from public colleges that limit the generalizability of the research findings. One limitation of the current study occurred during data collection as participants might show the social desirability bias while filling scales of sensation seeking, peer influence, and risk-taking behavior as girls had reported issues related to response bias (e.g., wild parties, preferring to play for money, it is better to go along 
with crowd than to make people angry at you), despite the fact that response biases have been well documented and continue to be a problematic issue while conducting researches on social issues. Cultural differences can also be viewed as limitation because Pakistani social network is different from western cultures. Sensation seeking is a personality trait that predicts risk-taking behavior in adolescents. Further, the role of personality as a whole can be examined in relation.

\section{Data Availability}

The data used to support the findings of this study are available from the corresponding author upon request.

\section{Disclosure}

This research work was done in the final year of Master's thesis as a research project at Institute of Applied Psychology University of the Punjab, Lahore.

\section{Conflicts of Interest}

The authors declare that they have no conflicts of interest.

\section{Acknowledgments}

The authors thank the administration of Institute of Applied Psychology University of the Punjab, Lahore, that published the abstract of this research work in yearly Psychological Abstracts Booklet in which they publish all the research work done by their students yearly. All the resources were utilized by the authors themselves.

\section{References}

[1] V. F. Reyna and F. Farley, "Risk and rationality in adolescent decision making," Psychological Science in the Public Interest, vol. 7, no. 1, pp. 1-44, 2006.

[2] L. Chassin, A. Hussong, and I. Beltran, “Adolescents' substance use," in Handbook of Adolescent Psychology, Lerner and L. Steinberg, Eds., vol. 1, pp. 723-763, John Wiley \& Sons, Hoboken, NJ, US, 3rd edition, 2009.

[3] M. Zuckerman, "Rose is a rose is a rose," Personality and Individual Differences, vol. 45, no. 4, pp. 110-112, 2008.

[4] D. M. Quadagno, "Sensation seeking and hormones in men and women: exploring the link," Hormones and Behavior, vol. 40, no. 5, pp. 396-402, 2001.

[5] D. O. Hebb, "Drives and the C. N. S. (conceptual nervous system)," Psychological Review, vol. 62, no. 4, pp. 243-254, 1955.

[6] M. J. Prinstein, C. S. Meade, and G. L. Cohen, "Adolescent oral sex, peer popularity, and perceptions of best friends' sexual behavior," Journal of Pediatric Psychology, vol. 28, no. 4, pp. 243-249, 2003.

[7] M. Hansen and G. Breivik, "Sensation seeking as a predictor of positive and negative risk behavior among adolescents," Personality and Individual Differences, vol. 1, no. 9, 1998.

[8] O. Ozmen and Z. H. Sümer, "Predictors of risk taking behavior among turkish adolescents," Personality and Individual Differences, vol. 50, no. 1, pp. 4-9, 2006.
[9] J. J. Arnett, "Emerging adulthood: what is it, and what is it good for," Child Development Perspectives, vol. 1, no. 2, pp. 68-73, 1996.

[10] M. A. Cyders, K. Flory, S. Rainer, and G. T. Smith, "The role of personality dispositions to risky behavior in predicting firstyear college drinking," Addiction, vol. 104, no. 2, pp. 193-202, 2009.

[11] W. J. Mark, G. Langewisch, and R. Frisch, "Gambling behavior and pathology in relation to impulsivity, sensation seeking, and risky behavior in male college students," Personality and Individual Differences, vol. 47, no. 7, pp. 763-768, 1998.

[12] R. D. Ravert, S. J. Schwartz, B. L. Zamboanga, S. Y. Kim, R. S. Weisskirch, and M. Bersamin, "Sensation seeking and danger invulnerability: paths to college student risk-taking," Personality and Individual Differences, vol. 47, no. 7, pp. 763-768, 2009.

[13] W. Qidwai, S. Ishaque, S. Shah, and M. Rahim, "Adolescent lifestyle and behaviour: a survey from a developing country," PLoS One, vol. 5, no. 9, pp. e12914-132, 2010.

[14] K. Green and M. krackmar, Targeting Adolescent Risk-Taking Behaviors: The Contributions of Egocentrism and SensationSeeking, Master thesis, Department of Communication at Rutgers, University New Brunswick, Fredericton, CA, USA, 2000.

[15] R. Velezemoro, K. Lacefield, and J. W. Roberti, "Perceived stress sensation seeking and college student abuse of the internet," Journal of Computer in Human Behavior, vol. 26, no. 6, pp. 1526-1530, 2010.

[16] R. H. Hoyle, M. C. Fejfar, and J. D. Miller, "Personality and sexual risk taking: a quantitative review," Journal of Personality, vol. 68, no. 6, pp. 1203-1231, 2000.

[17] K. A. Roeser, Personal and Social Factors in Risk Taking Behaviors of Emerging Adults, Wayne State University Dissertation Paper, Detroit, MI, USA, 2013.

[18] A. M. Farley, "Peer groups as a context for the socialization of adolescents' motivation, engagement, and achievement in school," Educational Psychologist, vol. 35, no. 2, pp. 101-111, 2000.

[19] J. J. Andrews, "Emerging adulthood: a theory of development from the late teens through the twenties," American Psychologist, vol. 55, no. 5, pp. 469-480, 2000.

[20] S. Kamila, "Peer influences and drug use among urban adolescents: family structure and parent-adolescent relationship as protective factors," Journal of Consulting and Clinical Psychology, vol. 29, no. 6, pp. 230-240, 1998.

[21] M. Warr and M. Stafford, "The influence of delinquent peers:

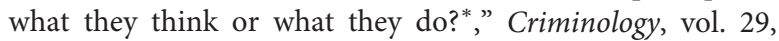
no. 4, pp. 851-866, 1991.

[22] R. Jessor, "Problem-behavior theory," in Risikoverhaltensweisen Jugendlicher, J. Raithel, Ed., VS Verlag für Sozialwissenschaften, Wiesbaden, Germany, 2001.

[23] I. Ajzen, "Attitudes, personality, and behavior," 2005, http:// www.people.ummas.edu/aizen/tpbrefs.html.

[24] R. A. Barkley, "Behavioral inhibition, sustained attention, and executive functions: constructing a unifying theory of ADHD," Psychological Bulletin, vol. 121, no. 1, pp. 65-94, 1997.

[25] M. Eamon and H. Cray, "Predicting antisocial behavior among latino young adolescents: an ecological systems analysis," American Journal of Orthopsychiatry, vol. 7, no. 5, pp. 99-111, 2005. 
[26] L. J. Knoll, L. Magis-Weinberg, M. Speekenbrink, and S.-J. Blakemore, "Social influence on risk perception during adolescence," Psychological Science, vol. 26, no. 5, p. 583, 2015.

[27] M. Gardner and L. Steinberg, "Peer influence on risk taking, risk preference, and risky decision making in adolescence and adulthood: an experimental study," Developmental Psychology, vol. 41, no. 4, pp. 625-635, 2005.

[28] A. K. Urberg, S. Jeoushyu, and J. Liang, "Peer influence in adolescent cigarette Smoking," Journal of Addictive Behaviors, vol. 15, no. 3, 1990.

[29] A. C. Fletcher, N. Darling, and L. Steinberg, "Parental monitoring and peer influences on adolescent substance use," Coercion and Punishment in Long-Term Perspectives, vol. 5, no. 4, pp. 259-271, 1995, https://www.researchgate.net/ 15002274.

[30] J. Fagan, F. E. Zimring, and J. Kim, "Declining homicide in New York city: a tale of two trends," Journal of Criminal Law and Criminology, vol. 8, no. 8, pp. 12-77, 1998.

[31] M. Hamburg, Exploring Peer Influences as a Path Way to Adolescence Substance Use in Nigeria, (Master Thesis), Hamburg University of Applied Sciences, Hamburg, Germany, 2013.

[32] L. Steinberg, "A social neuroscience perspective on adolescent risk-taking," Developmental Review, vol. 28, no. 1, pp. 78-106, 2008.

[33] L. Spear, The Developing Brain and Adolescent-Typical Behavior Patterns: An Evolutionary approach. Adolescent Psychopathology and the Developing Brain: Integrating Brain and Prevention Science, Oxford University Press, New York, NY, USA, 2007.

[34] D. R. Clasen and B. B. Brown, "The multidimensionality of peer pressure in adolescence," Journal of Youth and Adolescence, vol. 14, no. 6, pp. 451-468, 1985.

[35] J. Eldeleklioglu, "The relationship between aggressiveness, peer pressure and parental attitudes among Turkish high school students," Social Behavior and Personality: An International Journal, vol. 35, no. 7, 2007.

[36] B. B. Brown, Handbook of Adolescent Psychology, John Wiley \& Sons, Hoboken, NJ, USA, 2004.

[37] J. M. Twenge, "Social exclusion impairs self-regulation," Journal of Personality and Social Psychology, vol. 88, no. 4, pp. 589-604, 2005.

[38] D. Romer and M. Hennessy, "A biosocial-affect model of adolescent sensation seeking: the role of affect evaluation and peer-group influence in adolescent drug use," Prevention Science, vol. 8, no. 2, pp. 89-101, 2007.

[39] A. Bandura, "Social cognitive theory in cultural context," Applied Psychology, vol. 51, no. 2, pp. 269-290, 2002.

[40] T. Rosenbloom, "Risk evaluation and risky behavior of high and low sensation seekers," Social Behavior and Personality: An International Journal, vol. 31, no. 4, pp. 375-386, 2003.

[41] G. L. Rowland and R. E. Franken, "The four dimensions of sensation seeking: a confirmatory factor analysis," Personality and Individual Differences, vol. 7, no. 2, pp. 237-240, 1986.

[42] M. Zuckerman, Behavioral Expressions and Biosocial Bases of Sensation Seeking, Cambridge University Press, New York, NY, USA, 1994.

[43] M. Zuckerman, Theoretical Formulations of Sensation Seeking, Appleton-Century-Crofts, New York, NY, USA, 1969.

[44] L. Steinberg and S. B. Silverberg, "The vicissitudes of autonomy in early adolescence," Child Development, vol. 57, no. 4, pp. 841-851, 1986. 